\title{
Correction to: Experimental characterization of the hypersonic flow around a cuboid
}

\author{
Thomas W. Rees ${ }^{1}$ (D) Tom B. Fisher ${ }^{2} \cdot$ Paul J. K. Bruce ${ }^{1} \cdot \operatorname{Jim}$ A. Merrifield ${ }^{3} \cdot$ Mark K. Quinn $^{2}$
}

Published online: 12 November 2020

(c) The Author(s) 2020

Correction to: Experiments in Fluids (2020) 61:151 https://doi.org/10.1007/s00348-020-02975-x

- There is a typographical error in Equation 13, which should instead read:

$$
\left\{\begin{array}{l}
\frac{1}{\rho c_{p}(T)} \frac{\partial \lambda}{\partial t}=-\nabla(k(T) \nabla \lambda), \forall \mathbf{x} \in \Omega \\
\lambda(\mathbf{x}, t)=0, \forall \mathbf{x} \in \Omega, t=t_{f} \\
k(T) \frac{\partial \lambda}{\partial n}=2(T-Y), \forall \mathbf{x} \in S, 0<t<t_{f}
\end{array}\right.
$$

- The values in Table 4 should be updated to contain the values in the table below. The values in the published version of the table are incorrect, caused by a bug in the averaging procedure in the error processing software.

\begin{tabular}{lll}
\hline Error source & Variation $\Delta$ & $\Delta C_{H_{\%}}$ \\
\hline IHCP solution & - & $1.5 \%$ \\
Ambient temperature measurement $T_{a m b}[\mathrm{~K}]$ & $1.7 \%$ & $1.5 \%$ \\
Infrared Calibration $T_{I R}[\mathrm{~K}]$ & $\sigma=0.1 \mathrm{~K}$ & $1.5 \%$ \\
Model initial temperature distribution $T_{i}[\mathrm{~K}]$ & $2.7 \%$ & $1.5 \%$ \\
Material emissivity $\epsilon$ & $8.0 \%$ & $8.7 \%$ \\
Material thermal conductivity $k[\mathrm{~J} / \mathrm{kg} . \mathrm{K}]$ & $6.0 \%$ & $1.5 \%$ \\
Material specific heat capacity $c_{p}[\mathrm{~J} / \mathrm{kg} . \mathrm{K}]$ & $2.0 \%$ & $1.5 \%$ \\
Free-stream total temperature $T_{0}[\mathrm{~K}]$ & $2.5 \%$ & $6.9 \%$ \\
Free-stream total pressure $P_{0}[\mathrm{~Pa}]$ & $4.2 \%$ & $4.2 \%$ \\
\hline
\end{tabular}
This bug does not affect the results presented in Figure 6 nor does it affect the global error of $12 \%$ presented in the text of the document.

The original article can be found online at https://doi.org/10.1007/ s00348-020-02975-x.

Thomas W. Rees

thomas.rees10@imperial.ac.uk

1 Imperial College London, Exhibition Road, London SW7 2AZ, UK

2 University of Manchester, Oxford Road, Manchester M13 9PL, UK

3 Fluid Gravity Engineering Ltd., 1 West Street, Emsworth PO10 7DX, UK 